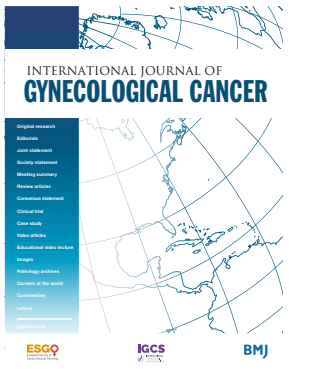

- Additional supplementary material is published online only. To view, please visit the journal online (http://dx.doi.org/ 10.1136/ijgc-2021-002761).

For numbered affiliations see end of article.

\section{Correspondence to} Dr Levon Badiglian-Filho, Gynecologic Oncology, ACCamargo Cancer Center, Sao Paulo, Brazil; levonbfilho@ gmail.com

SGO Meeting 2021 - Farr Nezhat Surgical Innovation Session

Accepted 21 June 2021 Published Online First 5 July 2021

\title{
Vaginectomy with trachelectomy followed by ileal neovagina reconstruction and uterine corpus sparing for vaginal melanoma
}

Levon Badiglian-Filho (D) , ${ }^{1}$ Monica Lucia Rodrigues, ${ }^{2}$ Rute Facchini Lellis, ${ }^{3}$

Jaqueline Munaretto Timm Baiocchi, ${ }^{4}$ Joao Paulo da Silveira Nogueira Lima, ${ }^{5}$ Glauco Baiocchi (D) 1

Vaginectomy is surgery with limited indications. Usually, it is performed with concurrent hysterectomy even if the uterus is not affected by the neoplastic disease. However, it is possible to spare the uterine corpus and connect it to a neovagina. We present a nulliparous patient with vaginal melanoma and describe this step-by-step procedure. Written informed consent was obtained from all subjects.

The surgery proceeded as a radical abdominal trachelectomy ${ }^{1}$ except that there was no need for extensive parametrectomy. Epinephrine $(1 \mathrm{mg})$ diluted in the saline solution $(200 \mathrm{~mL})$ was used to facilitate vaginal dissection.
After vaginal dissection up to its distal portion, two mixter forceps were used to clamp the distal border of the vagina, and the incision was made distally to it (Figure 1).

The proximal incision was made on the uterine cervix sparing $1 \mathrm{~cm}$ of it, close to the uterine isthmus, and a cervical cerclage was performed.

A foley catheter was attached to the uterine corpus to guide the neovagina pathway.

There are different possibilities to construct a neovagina (Online Supplemental Table 1), from the colon to abdominus myocutaneous flap, but we decided to use an ileal conduit to minimize the

\section{GYNECOLOGICAL CANCER}

\section{Vaginectomy with trachelectomy followed by ileal neovagina reconstruction and uterine corpus sparing for vaginal melanoma.}

Badiglian-Filho, L; Rodrigues, ML; Lellis, RF; Baiocchi, JMT; Lima, JPSN; Baiocchi, G.

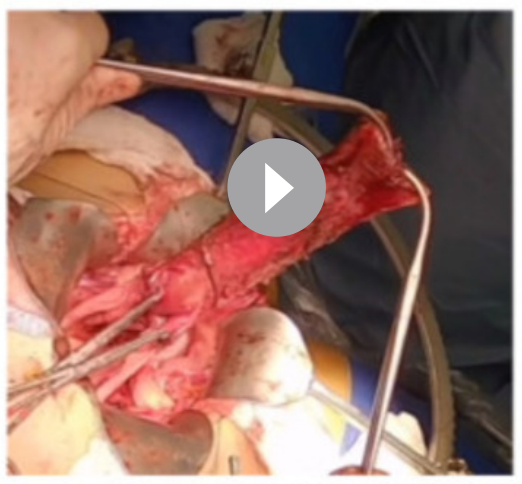

(C) IGCS and ESGO 2021. No commercial re-use. See rights and permissions. Published by BMJ.

\begin{tabular}{l} 
To cite: Badiglian-Filho L, \\
Lucia Rodrigues M, \\
Facchini Lellis $\mathrm{R}$, et al. \\
Int J Gynecol Cancer \\
2021;31:1301-1302. \\
\hline
\end{tabular}

Video 1 Vaginectomy with trachelectomy followed by ileal neovagina reconstruction and uterine corpus sparing for vaginal melanoma. 


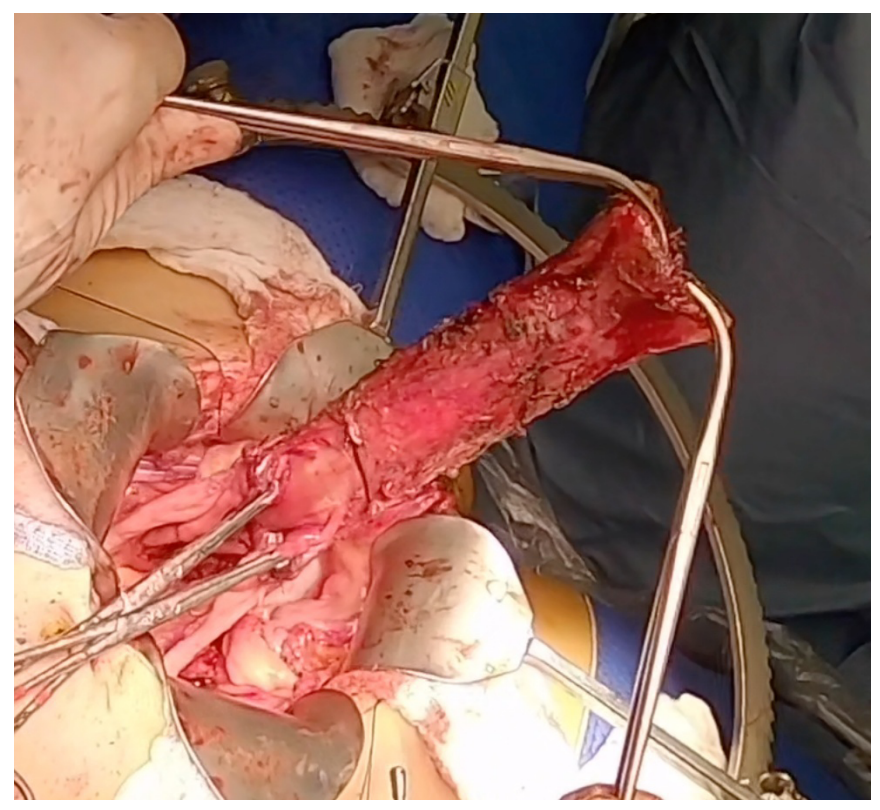

Figure 1 Vaginectomy just before the incision on the uterine cervix.

possibility of anastomosis fistula and because her mesocolon was too short. ${ }^{2-4}$ An ileal segment was carefully chosen, regarding its blood supply and it was sutured to the uterine corpus. After that, the distal end of the neovagina was sutured to the distal vagina and the round ligaments were reconnected.

The ileal anastomosis was performed using the Barcelona technique, in which a lateral-lateral entero-anastomosis is made by a stapler creating a common channel, and then, the same stapler is used to close the opening of this common channel.

Surgery time was 630 min and estimated blood loss was $400 \mathrm{~mL}$. The foley catheter used to guide the neovagina came out by itself on the 10th post-operative day (Video 1).

The pathology report confirmed mucosal melanoma and margins were negative as well as lymph nodes.

Magnetic resonance on late postoperative term demonstrated a good location of the neovagina, and she resumed regular menstrual activity.

Regarding bladder activity, she had some occasional urinary incontinence after surgery that recovered with physiotherapy. The bladder foley catheter was removed on the 24th postoperative day.

On the 140th postoperative day, PET-CT evidenced positive sacral and iliac lymph nodes, and later, she presented nodules in the lungs, neck, and retroperitoneal space. She is under combined immunotherapy (Ipilimumab $1 \mathrm{mg}+$ nivolumab $3 \mathrm{mg}$ every 21 days).

We conclude that it is possible to remove almost the entire vagina with uterine sparing and acceptable transitory bladder dysfunction.

\section{Author affiliations}

${ }^{1}$ Gynecologic Oncology, ACCamargo Cancer Center, Sao Paulo, Brazil

${ }^{2} \mathrm{Head}$ and Neck Surgery and Otorhinolaryngology, ACCamargo Cancer Center, Sao Paulo, Brazil

${ }^{3}$ Pathology, ACCamargo Cancer Center, Sao Paulo, Brazil

${ }^{4}$ Instituto Oncofisio, Sao Paulo, Brazil

${ }^{5}$ Medical Oncology, ACCamargo Cancer Center, Sao Paulo, Brazil

Twitter Glauco Baiocchi @glaucobaiocchi

Contributors Conception: LBF. Surgery performing: LBF and MLR. Pathology report: RFL. Physiotherapy: JMTB. Critical review: GB and JPSNL. Supervision: GB.

Funding The authors have not declared a specific grant for this research from any funding agency in the public, commercial, or not-for-profit sectors.

Competing interests None declared.

Patient consent for publication Not required.

Provenance and peer review Not commissioned; externally peer reviewed.

Data availability statement All data relevant to the study are included in the article.

Supplemental material This content has been supplied by the author(s). It has not been vetted by BMJ Publishing Group Limited (BMJ) and may not have been peer-reviewed. Any opinions or recommendations discussed are solely those of the author(s) and are not endorsed by BMJ. BMJ disclaims all liability and responsibility arising from any reliance placed on the content. Where the content includes any translated material, BMJ does not warrant the accuracy and reliability of the translations (including but not limited to local regulations, clinical guidelines, terminology, drug names and drug dosages), and is not responsible for any error and/or omissions arising from translation and adaptation or otherwise.

\section{ORCID iDs}

Levon Badiglian-Filho http://orcid.org/0000-0001-8741-166X

Glauco Baiocchi http://orcid.org/0000-0002-8193-5582

\section{REFERENCES}

1 Abu-rustum NR, Sonoda Y, Black D. Fertility-sparing radical abdominal trachelectomy for cervical carcinoma: technique and review of the literature 2006;103:807-13.

2 D'Souza DN, Pera M, Nelson $\mathrm{H}$, et al. Vaginal reconstruction following resection of primary locally advanced and recurrent colorectal malignancies. Arch Surg 2003;138:1340-3.

3 Bouman M-B, van Zeijl MCT, Buncamper ME, et al. Intestinal vaginoplasty revisited: a review of surgical techniques, complications, and sexual function. J Sex Med 2014;11:1835-47.

4 Zbar AP, Shenoy RK, Chiappa A. Extended abdominoperineal resection in women: the Barbadian experience. Int Semin Surg Oncol 2007;4:1-6. 